\title{
Relationship Between Meat Quality Characteristics, Intramuscular Fat and Marbling in Greek Cattle Carcasses
}

\author{
Masouras P.K. ${ }^{1}$, Nikolaou K. ${ }^{1,2}$, Laliotis G.P. ${ }^{1 *}$, Koutsouli P. ${ }^{1}$, Bizelis I. ${ }^{1}$
}

${ }^{1}$ Laboratory of Animal Breeding and Husbandry, Department of Animal Science, Agricultural University of Athens, Athens, Iera Odos 75, GR 11855, Athens, Greece; ${ }^{2}$ Department of Bovine Sector and Equity, Directorate General of Agriculture, Directorate of Animal Husbandry Systems, Hellenic Ministry of Rural Development and Food, Veranzerou 46, GR 10176, Athens, Greece.

\begin{abstract}
Marbling and intramuscular fat (IMF) although influence consumers' preferences are not used for grading purposes of beef carcasses and meat cuts in Europe. In Greece, a variety of breeds is used for beef production, but their meat quality characteristics have not yet been evaluated. The aim of the study was to determine meat quality characteristics on samples obtained from cattle reared for meat purposes in Greece and to investigate if any correlation between these characteristics, IMF and marbling exists. Thirty steak cuts (12 $2^{\text {th }}$ thoracic rib) obtained from carcasses of both sexes of three different group of breeds (Holstein, Greek Red breed, crossbreds) were used to determine color parameters $\left(L^{*}, a^{*}, b^{*}\right)$, drip and cooking loss, tenderness and IMF. Marbling was estimated using an image analysis approach. Samples of Greek Red had higher $a^{*}$ value $(\mathrm{P}<0.05)$ compared to those obtained from crossbreds. Female samples revealed higher $(\mathrm{P}<0.05)$ values of $L^{*}$ compared to male. Significant correlations were observed between some of the determined meat quality parameters. A strong correlation $(r=0.798 ; \mathrm{P}<0.01)$ was noted between IMF and marbling content. The regression analysis between IMF and marbling resulted in a moderate predicted ability $\left(\mathrm{R}^{2}\right.$ $=0.64$ ) of IMF based on the estimated marbling values. The findings provide novel information for meat quality of commercial cuts in Greece and offer a valuable and facile tool for predicting IMF content by marbling values, enforcing the implementation of such an approach in larger data sets.
\end{abstract}

Keywords | Marbling, Intramuscular fat, Meat quality, Carcass, Beef, Cattle breeds

Received | October 15, 2021; Accepted | December 21, 2021; Published | January 15, 2022

${ }^{*}$ Correspondence | Laliotis G.P., Laboratory of Animal Breeding and Husbandry, Faculty of Animal Science, Agricultural University of Athens, Iera Odos 75, GR 11855, Athens, Greece; Email: glaliotis@aua.gr

Citation | Masouras PK, Nikolaou K, Laliotis GP, Koutsouli P, Bizelis I (2022). Relationship between meat quality characteristics, intramuscular fat and marbling in Greek cattle carcasses. Adv. Anim. Vet. Sci. 10(3): 506-513.

DOI | http://dx.doi.org/10.17582/journal.aavs/2022/10.3.506.513

ISSN (Online) | 2307-8316

\section{INTRODUCTION}

$\mathrm{M}$ eat, especially that originated from beef, is considered of utmost importance part of human diet due to its valuable nutrient content (Scollan et al., 2006). Meat beef production is, also, one of the most valuable driver of world's livestock economy, with significant contribution to local, national and international trade, economy and society cohesion. The European Union is ranked at the third position in beef production after United States and Brazil. Taken together the beef production of the aforementioned countries represents roughly the $50 \%$ of world's beef (FAO,
2021).

Beef carcass characteristics affect not only meat quality but also farmers' profitability and consumers' preferences. Overall meat quality is determined by a variety of factors including among others intramuscular fat, water absorption, color and $\mathrm{pH}$. Marbling, which is defined as the amount and spatial distribution of visible white flecks of intramuscular fat being present in the lean of the longissimus dorsi (LD) muscle, is considered, also, as an important organoleptic characteristic affecting many qualitive and palatability characteristics of meat such as color, tenderness, juiciness 
and flavor(AMSA, 2001).Marbling, also, affects consumers' eating quality preferences (Bonny et al., 2018). However, marbling and, therefore, intramuscular fat content is variable and are affected by many factors including breed, sex, diet, age and weight at slaughter (Bosch et al., 2012). In addition, the optimal marbling score is very subjective as it depends on countries' standards, consumers' demands and implemented technological processes (Font-i-Furnols et al., 2012).

Many countries (i.e., Australia, United States, Japan) developed systematic standards for evaluating marbling as a proxy to meet consumers' demands (Polkinghorne and Thompson, 2010). These standards are based on numeric scales according to standardized images of the target meat cuts. In European Union, the SEUROP system, that is implemented compulsory for beef carcasses classifications takes into account only carcass conformation and fat cover and not the marbling score of meat cuts (Reg. EU 1308/2013). Specifically, the classes namely E, U, R, O, and $\mathrm{P}$ are used for conformation purposes, with $\mathrm{E}$ class denoting carcasses with the best conformation. An extra $S$ class can be used for carcasses with extremely good muscle development (i.e., double-muscled individuals). Fat cover is, also, assessed on a five-point scale (1-5). In addition, although it is based on widely accepted indicators, such as age, sex, muscle shape, it does not consider carcass as a complex and heterogeneous entity (Ellies-Oury et al., 2020). Liu et al. (2020) reported, also, that SEUROP fat scores explain a slight proportion of the variance in marbling score, depending on the carcass category (bull, heifer etc.), rendering it as a weak tool for marbling estimation. The lack of a strong and clear link between sensory scores and European carcass classification standards shows that the European beef industry cannot rely on them and needs, also, to integrate alternative measures into SEUROP system in order to enable meat quality and to deliver consistent beef quality to the consumers (Bonny et al., 2018). In this line, image analysis methods, that have been well documented as valuable and ease tools for beef carcasses or marbling scoring (Craige et al., 2012; Čandek-Potokar et al., 2015), could form an alternative.

The beef sector in Balkan peninsula and especially in Greece has a great interest due to the peculiarities met in the farming systems, especially by terms of the variety in breeds intended for meat production (Nikolaou et al., 2020). Local Greek breeds do not meet the qualitive and quantitative demands of the sector and, therefore, farmers usually import heterogeneous foreign meat type purebreeds and crossbreds or use crosses between local (autochthonous) breeds and beef breeds or even Holstein breed. A typical example of crossbred animals used for meat production in Greece is Greek Red, which has been recently recognized as a Greek beef type breed. The Greek Red was formed by continuous crossbreeding of local cattle (i.e., Brachyceros) with exotic bulls of dual-purposed Schwyz or Simmental breeds or with meat-type Limousin bulls (DAD-IS, 2021).

Even though a large number of beef breeds reared and slaughtered in Greece, there is a lack of information regarding their meat quality characteristics. Thus, the present study aims to: (i) determine meat quality characteristics ( $\mathrm{pH}$, color, tenderness, drip loss, cooking loss) and intramuscular fat (IMF) content on meat samples obtained from cattle reared in Greece; (ii) estimate the marbling percentage (MP) using a computer based method (image analysis approach), which could further serve as a facile method for a quick evaluation of marbling content in meat chain industry independently from chemical analyses and iii) investigate if any correlation between the determined values of IMF and MP exist, which could serve as a proxy for an estimation of IMF for further implications.

\section{MATERIALS AND METHODS}

\section{ANIMALS AND MEAT SAMPLES}

A total of 30 beef steak cuts (12 $12^{\text {th }}$ thoracic rib) obtained from carcasses of both sexes and of three different group of breeds were used in the study. Animals were bred under intensive farming conditions in different places of northern and central Greece. Carcass samples were obtained 24 hours after slaughter from the following group of breeds: Holstein $(n=8)$, Greek Red $(n=9)$ and crossbreds $(n=13)$. Crossbred carcasses were considered those originated from a cross of local breeds and cosmopolitan beef breeds. Eleven samples were from female carcasses, while the rest $(n=19)$ from male carcasses. According to the official documents of the slaughterhouses, the slaughter age of the animals was between 8-24 months.

\section{Carcass QUALiTy PARAMETERS' MEASUREMENT}

Muscle $\mathrm{pH}$ at $24 \mathrm{~h}$ postmortem was measured directly on the longissimus thoracis muscle of the $12^{\text {th }}$ thoracic rib using a Sentron 1001 pH System (Roden, Netherlands) model from the left side of the carcass. $\mathrm{pH}$ meter calibrated in buffers at pH 4.0 and 7.0 (Merck, Darmstadt, Germany) at ambient temperature. For color measurements, the part of longissimus thoracis muscle between $12^{\text {th }}$ and $13^{\text {th }}$ ribs were sliced across the fibers, left exposed to the air at room temperature for blooming during $30 \mathrm{~min}$ and measured (3 measurements per sample) using a Miniscan XE Chroma Meter (HunterLab, Reston, VA, U.S.A.) set on the $L^{*}, a^{*}, b^{*}$ system. A white and a black tile were used as standard. After color measurements, samples were stored at $4{ }^{\circ} \mathrm{C}$ for further analyses.

On the third day postmortem, the rib-eye area of the longissimus thoracis muscle from each sample of the $12^{\text {th }}$ 
steak, was weighted and placed in plastic bags, cooked in a water bath at $70{ }^{\circ} \mathrm{C}$ for $1 \mathrm{~h}$ and then left under running water for $45 \mathrm{~min}$. The sample was weighed again to estimate the percentage of cooking loss (\%). Six sub samples with a cross section of $1 \mathrm{~cm}^{2}$ were cut parallel to the muscle fibers and shear force value of the longissimus thoracis muscle was measured using a Warner Bratzler (WB) shear blade fitted to a Zwick Testing Machine Model Z2.5/TN1 S (Zwick $\mathrm{GmbH}$ and Co, Germany). Peak force values in Newtons were recorded.

For drip loss (DL) determination (percentage of released water), muscle samples weighing about $500 \mathrm{mg}$ (P1) were placed between filter paper and two plastic pieces and then pressed for $5 \mathrm{~min}$, using a weight of $10 \mathrm{~kg}$. The muscle samples were then removed and re-weighed (P2). Percentage of released water was estimated as DL $(\%)=$ $\{(\mathrm{P} 1-\mathrm{P} 2) / \mathrm{P} 1\} \times 100$.

Measurement of intramuscular total lipids was performed using the method described by Folch et al. (1957). Tissue samples were homogenized using a 2:1 (v/v) chloroform/ methanol mixture (Sigma-Aldrich Chemical, Steinheim, Germany) to a final dilution of 20 -fold the volume of the tissue sample. The crude extract was mixed with $20 \%$ of its volume with water and left overnight for the separation of two liquid phases. The lower phase contained the tissue lipids.

\section{IMAGE ANALYSIS OF MARBLING}

The muscle surface area at the 12th rib eye section of each steak was photographed by a digital camera (Canon EOS 7D) from a height of $40 \mathrm{~cm}$ height without using flashlight. Each sample was photographed over a blank white surface with a ruler close to the meat cut to obtain the pixel: $\mathrm{mm}$ ratio for further image analysis. To determine the percentage of marbling particles each image was analyzed using Image J software (Schneider et al., 2012) following the procedure previously described (Giaretta et al., 2018) with slight modifications based on software's documentation. The steps that were followed were: Firstly, the scale pixel/mm was set converting pixels to $\mathrm{mm}$ units using a ruler presented in each photo. Then, each image was splitted into the three separately color channels (RedGreen-Blue) and the channel with the lowest background noise (i.e. Green in the present study) was selected. The image on the selected color channel was converted into grey scale 8-bit image and the threshold, using the Otsu method, was adjusted to highlight the marbling fat (white spot particles) over muscle background (black). The part of the image containing the area of interest (rib-eye) was manually selected and the analysis of marbling fat particles was further performed. The minimum size of fat particles considered as marbling fleck was set at $1 \mathrm{~mm}$ (Lee and Choi, 2019). The percentage of marbling area (\%) was calculated as the marbling particles area related to the image selected area expressed as percentage (Figure 1). To eliminate subjective operator differences, image acquisition and measurements (three measurements per sample) were conducted by a single experienced operator.

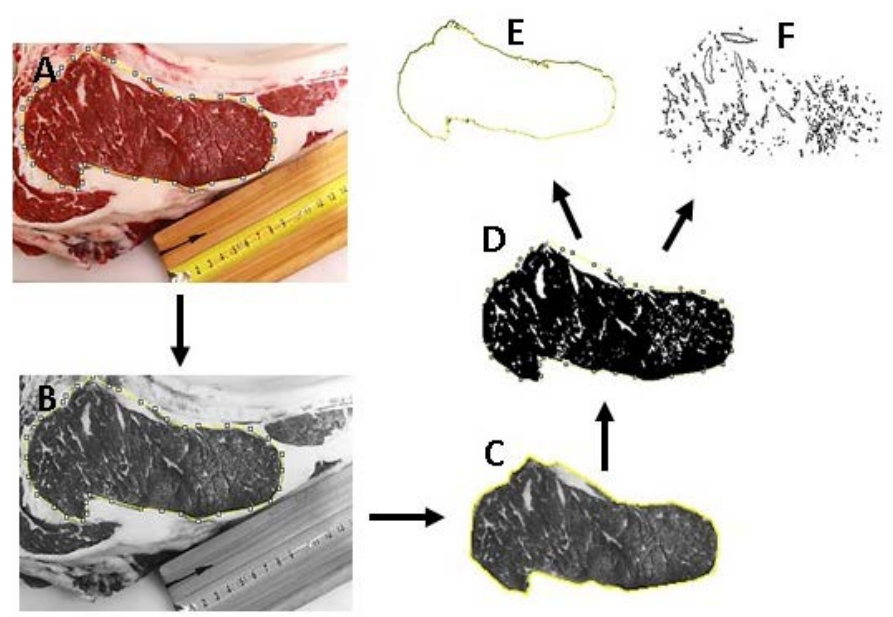

Figure 1: Image analysis method analysis using J software for estimating marbling percentage. The longissimus thoracis muscle cross-section (rib eye area) was firstly selected (A), converted into 8-bit image (B) and then the selected area was separated (C) and binarized (D) to highlight the marbling fat (white spot particles) over muscle background (black). Then, the binarized image was separated into two images; one showing the whole selected rib eye area (E) and one presenting spots areas of spotted particles (F). Marbling percentage was calculated as the marbling particles area $(\mathrm{F})$ related to the area of the selected rib-eye area $(\mathrm{E})$.

\section{STATISTICAL ANALYSis}

A Pearson correlation was conducted in order to investigate any correlation between the examined parameters. In addition, the following multivariate General Linear Model was used to examine the effect of breed and sex on the determined carcass quality characteristics:

$$
Y_{i j k}=\mu+B_{i}+S_{j}+\operatorname{Cov}(S w)_{k}+e_{i, j, k}
$$

Where,

$\mathrm{Y}_{\mathrm{i}, \mathrm{j}, \mathrm{k}}=$ the examined quality trait; $\mu=$ the mean; $\mathrm{B}_{\mathrm{i}}=$ the fixed effect of breed ( $\mathrm{i}=1$ : Holstein; 2: Greek Red; 3: Crossbreds); $S_{j}=$ the fixed effect of sex $(j=1:$ male; 2 = female $) ; \operatorname{Cov}(\mathrm{Sw})_{k}=$ the covariance of the animal's slaughtered weight; $e_{i j k}=$ the random error.

The effect of "Breed $x$ Sex" did not found statistically significant $(\mathrm{P}>0.05)$ and, thus, it was excluded from the model. Post-Hoc tests (pairwise comparisons) were conducted using a Bonferroni test correction. In order to further examine the possibility of predicting intramuscular fat (IMF) content using the estimated marbling values 
derived from image analysis process, a linear regression analysis was conducted between chemical determined values of IMF and the values estimated by Image analysis. All statistical analyses were performed using SPSS v.26 (IBM, 2019) setting a significance level at $\mathrm{P}<0.05$.

\section{RESULTS}

Table 1 represents the effect of breed and sex on the determined meat quality parameters and mean carcass weight. Overall mean carcass weight was $289.19 \pm 16.34$ $\mathrm{kg}$. A significant $(\mathrm{P}<0.05)$ higher value for $a^{*}$ parameter in meat samples from Greek Red $(19.02 \pm 1.12)$ was observed compared to the respective samples of crossbreds (15.79 \pm 1.06). The $\mathrm{pH}$ value as well as tenderness and drip loss did not affect by breed or sex $(\mathrm{P}>0.05)$. IMF and marbling percentage value determined in each sample are shown in Figure 2. IMF was found significant $(\mathrm{P}<0.05)$ higher in meat samples from Holstein $(2.99 \pm 0.47 \%)$ compared to the respective value of crossbreds $(1.49 \pm 0.42 \%)$. Regarding marbling, meat samples from Holstein breed found to have significant $(\mathrm{P}<0.05)$ higher values $(3.62 \pm$ $0.65 \%)$ of marbling compared to the respective samples of Greek Red (1.74 $\pm 0.60 \%)$ and crossbreds $(1.25 \pm 0.57 \%)$. The same was also noted for marbling between samples of Greek Red and crossbreds $(\mathrm{P}<0.05)$. Sex affected only the $L^{*}$ parameter of color. Meat samples from female animals had significant $(\mathrm{P}<0.05)$ higher values $(37.36 \pm 1.47)$ of $L^{*}$ compared to the respective samples originated from male animals (32.82 \pm 1.01$)$.

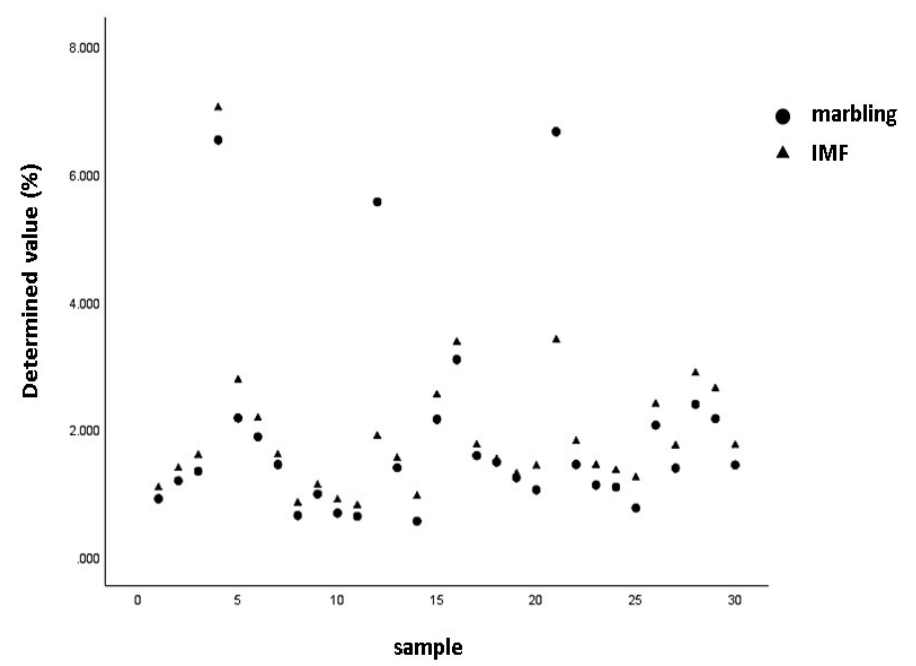

Figure 2: Scatterplot of intramuscular fat (IMF; depicted as triangle) and marbling percentage (depicted as dots) in the analyzed samples (Holstein: samples 1-4, 12, 18, 20, 21; Greek Red: 5-7, 26-30; Crossbreds: 8-11, 13-17, 2225).

Correlation coefficients between the determined meat quality characteristics are shown in Table 2. A statistically significant correlation was noted between i) $L^{*}$ and the percentage of cooking loss $(r=0.391 ; \mathrm{P}<0.05)$, ii) $a^{*}$ and $b^{*}$ color parameters $(r=0.919 ; \mathrm{P}<0.01)$, iii) tenderness and $L^{*}(r=0.409 ; \mathrm{P}<0.05)$ and iv $)$ the percentage of chemical determined IMF and the estimated marbling percentage using an image analysis approach $(r=0.798 ; \mathrm{P}<0.01)$.

Regression analysis results and the predicted equitation between the estimated marbling values and the chemical determined IMF content are shown in Figure 3. The estimated $R^{2}$ of the model was $0.64(\mathrm{P}<0.001)$, the constant $(a)$ was 0.80 and the slope $(b)$ of the regression line was estimated $0.60(\mathrm{P}<0.001)$.

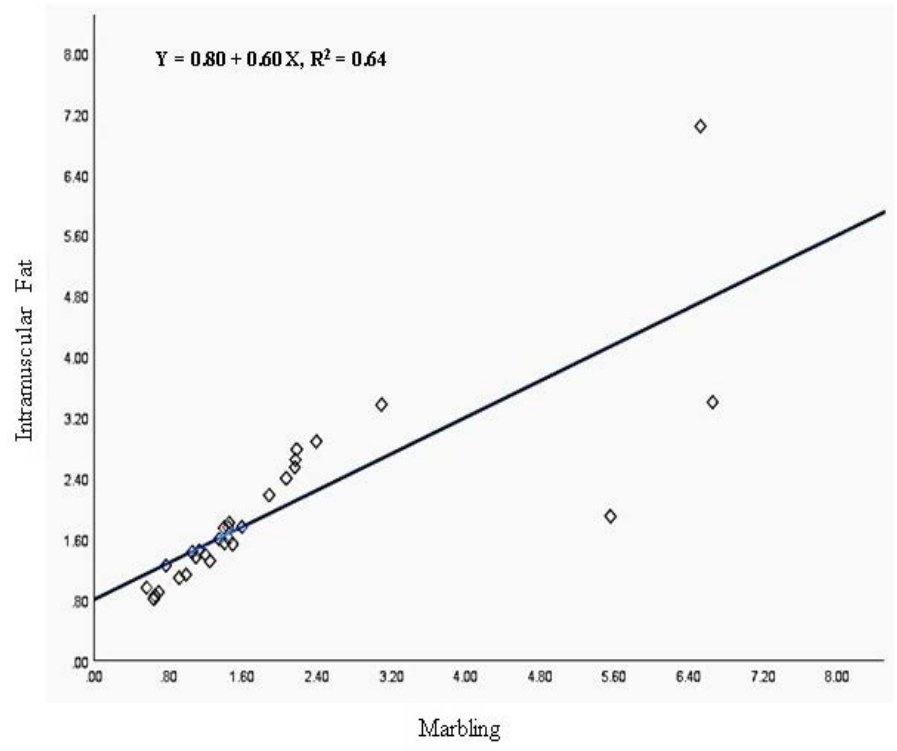

Figure 3: Linear regression analysis between the chemical determined intramuscular fat (IMF \%) and marbling (\%) estimated by image analysis.

\section{DISCUSSION}

Many studies have been previously conducted as an attempt to connect meat quality characteristics (color, tenderness, marbling, intramuscular fat etc.) with breed, sex or conformation scores of carcasses. These studies have been, mainly, focused in samples obtained from pure beef breeds or crosses between them. In many countries where beef livestock sector is not so well developed, a wide variety of carcass quality is observed as a result of the heterogeneous genetic material that is used. A typical example of such situation is Greece, where beef production is based mainly in crosses between local breeds and meat type breeds (i.e., Limousin), heterogeneous crosses between meat type breeds or Holstein calves. Herein, we attempted to determine meat quality characteristics from meat samples obtained from breeds reared for beef in Greece. In, addition, we tried using a computer-based method to estimate marbling percentage and to further correlated it with the chemical determined IMF, which may be used as a proxy to estimate IMF for future consumers' purposes. 
Table 1: Effect of breed and sex on the determined meat quality characteristics of M. longissimus thoracis. Values are presented as least squares mean \pm standard error.

\begin{tabular}{llllll} 
Parameter & \multicolumn{3}{c}{ Breed } & \multicolumn{2}{c}{ Sex } \\
& Holstein & Greek Red & Crossbreds & Male & Female \\
$\mathrm{pH}$ & $5.54^{\mathrm{a}} \pm 0.32$ & $5.77^{\mathrm{a}} \pm 0.29$ & $5.39^{\mathrm{a}} \pm 0.279$ & $5.63^{\mathrm{a}} \pm 0.22$ & $5.48^{\mathrm{a}} \pm 0.29$ \\
$\mathrm{~L}^{*}$ (lightness) & $34.68^{\mathrm{a}} \pm 1.55$ & $34.84^{\mathrm{a}} \pm 1.40$ & $35.74^{\mathrm{a}} \pm 1.37$ & $32.82^{\mathrm{a}} \pm 1.01$ & $37.36^{\mathrm{b}} \pm 1.47$ \\
$\mathrm{a}^{*}$ (Redness) & $16.91^{\mathrm{a}, \mathrm{b}} \pm 1.20$ & $19.02^{\mathrm{a}} \pm 1.12$ & $15.75^{\mathrm{b}} \pm 1.06$ & $17.52^{\mathrm{a}} \pm 0.83$ & $16.96^{\mathrm{a}} \pm 1.14$ \\
$\mathrm{~b}^{*}$ (Yellowness) & $14.82^{\mathrm{a}} \pm 1.19$ & $17.31^{\mathrm{a}} \pm 1.10$ & $14.73^{\mathrm{a}} \pm 1.06$ & $15.19^{\mathrm{a}} \pm 0.82$ & $16.05^{\mathrm{a}} \pm 1.13$ \\
Cooking loss \% & $23.24^{\mathrm{a}} \pm 1.94$ & $24.53^{\mathrm{a}} \pm 1.80$ & $24.70^{\mathrm{a}} \pm 1.71$ & $25.55^{\mathrm{a}} \pm 1.33$ & $22.77^{\mathrm{a}} \pm 1.84$ \\
Drip loss \% & $27.87^{\mathrm{a}} \pm 2.71$ & $30.07^{\mathrm{a}} \pm 2.52$ & $32.29^{\mathrm{a}} \pm 2.39$ & $30.73^{\mathrm{a}} \pm 1.87$ & $29.42^{\mathrm{a}} \pm 2.57$ \\
Tenderness (Nt) & $59.18^{\mathrm{a}} \pm 8.87$ & $68.41^{\mathrm{a}} \pm 8.23$ & $71.52^{\mathrm{a}} \pm 7.82$ & $72.29^{\mathrm{a}} \pm 6.09$ & $60.45^{\mathrm{a}} \pm 8.38$ \\
IMF \% & $2.99^{\mathrm{a}} \pm 0.47$ & $1.88^{\mathrm{a}, \mathrm{b}} \pm 0.43$ & $1.49^{\mathrm{b}} \pm 0.42$ & $1.61^{\mathrm{a}} \pm 0.32$ & $2.63^{\mathrm{a}} \pm 0.45$ \\
Marbling \% & $3.62^{\mathrm{a}} \pm 0.65$ & $1.74^{\mathrm{b}} \pm 0.60$ & $1.25^{\mathrm{c}} \pm 0.57$ & $1.67^{\mathrm{a}} \pm 0.44$ & $2.74^{\mathrm{a}} \pm 0.61$ \\
Slaughter weight $(\mathrm{Kg})$ & $253.40^{\mathrm{a}} \pm 25.44$ & $247.61^{\mathrm{a}} \pm 16.02$ & $340.00^{\mathrm{b}} \pm 26.53$ & $327.81^{\mathrm{a}} \pm 20.67$ & $222.49^{\mathrm{b}} \pm 9.32$
\end{tabular}

a,b,c Different superscripts in the same row of each factor (breed or sex) indicates statistically significant differences $(\mathrm{P}<0.05)$.

Table 2: Pearson correlation coefficients ( $\mathrm{r}$ ) between the determined meat quality characteristics.

$\begin{array}{lllllllll}\text { Parameters } & \boldsymbol{L}^{*} & \boldsymbol{a}^{*} & \boldsymbol{b}^{*} & \text { Cooking loss \% } & \text { drip loss \% } & \text { Tenderness } & \text { Marbling \% } & \text { IMF \% } \\ \mathrm{pH}_{24} & -0.416 & -0.580 & -0.573 & -0.182 & 0.052 & -0.454 & 0.010 & -0.004 \\ L^{*} & & 0.009 & 0.209 & 0.391^{*} & -0.017 & 0.409^{*} & 0.239 & -0.091 \\ \mathrm{a}^{*} & & & 0.919^{* *} & 0.027 & -0.182 & -0.010 & 0.029 & 0.016 \\ b^{*} & & & & 0.011 & -0.195 & 0.126 & 0.064 & -0.045 \\ \text { cooking loss (\%) } & & & & & 0.241 & 0.396^{*} & 0.031 & -0.164 \\ \text { drip loss (\%) } & & & & & & -0.035 & -0.312 & -0.172 \\ \text { Tenderness (Nt) } & & & & & & & 0.053 & -0.151 \\ \text { Marbling \% } & & & & & & & & 0.798^{*}\end{array}$

${ }^{*} P<0.05{ }^{* *} P<0.01$

The first finding emerging from our study is that color parameters were affected by breed or sex only in regard to $a^{*}$ and $L^{*}$ parameter, respectively. Generally, the herein determined meat quality values are comparable with beef quality characteristics reported previously (Prieto et al., 2010; Coleman et al., 2016). Our estimated $a^{*}$ values were higher compared to that reported by previous studies, that examined samples from cosmopolitan beef breeds (i.e., Limousin, Simental, Angus) or their crossbreds (Muchenje et al., 2008; Coleman et al., 2016). Contrary, higher estimated mean values for $a^{*}$ have been reported for Limousin and Angus breeds (Prieto et al., 2010), but our values fall into their reported range of $a^{*}$ value. Such differences in meat color among breeds can be attributed to variations in IMF and/or meat moisture content (Mancini and Hunt, 2005). Indeed, between the two examined groups (Greek Red and crossbreds) significant differences in IMF content were observed, and a higher drip loss (although not significant) was, also, noted in the examined samples of the crossbreds, which could explain the observed differences.

The higher $L^{*}$ value observed, in female meat samples compared to males are in accordance to previously reported studies (Zhang et al., 2010; Marenčić et al., 2018). Generally, higher $\mathrm{pH}$ values have been correlated with darker color in bull meat, due to the more rapid glycolysis appeared postmortem (Immone et al., 2000). Higher degree of intramuscular fat (marbling) can, also, result to higher $L^{*}$ (Page et al., 2001). Even statistically not significant, higher IMF and slightly higher $\mathrm{pH}$ values were noted in female meat samples (Table 1), possibly attributing to the higher observed $L^{*}$ value.

In regard to $\mathrm{pH}$ values, drip loss and tenderness, the determined values are within the range reported in previous studies (Page et al., 2001; Coleman et al., 2016; Marenčić et al., 2018). Although these parameters can be affected by many factors like i.e., genotype, feeding, treatment before or after slaughter, treatment of carcass after slaughter etc., this was not observed in our study possibly either due to the high variability observed in some values (i.e., tenderness) or due to the fact that many of these parameters are corelated to each other. The noted range of slaughter weight $(247.61-340 \mathrm{~kg})$ is considered lower compared to that reported by previous studies (over $420 \mathrm{~kg}$ ) 
conducted on meat type breeds or other crossbreeds. This can be explained either by different consumers' demands by terms of carcass characteristics or to differences on the implemented farming systems.

Moreover, samples of Greek Red breed showed significant different values of IMF (\%) and marbling (\%), compared to the other two breeds. This is in accordance with previously studies stating that both characteristics are affected by breed (Dinh et al., 2010; Miguel et al., 2011). Interestingly, the determined IMF (\%) corresponds to lower classes (i.e., traces or slight) of marbling score classification in meat quality standards adapted by non-European countries (USA, Japan, etc.), possibly reflecting a different consumers' preferences. Indeed, many European consumers prefer nowadays beef meat with low fat content as a healthier nutrient approach, which is slightly opposite to the respective preferences of other countries that prefer mainly beef cuts with medium or high marbling (i.e., USA).

Another finding revealed from the present study is the significant correlations observed between some meat quality parameters and chemical composition traits. Cooking loss was positively linked $(r=0.409)$ with shear force, which is in agreement with previous studies (Monteiro et al., 2013). Tenderness is influenced more by cooking loss than any other physiochemical trait (Monteiro et al., 2013). Interestingly, a strong correlation was observed between $a^{*}$ and $b^{*}$ parameters. There is no physiochemical profound explanation as to why this correlation observed, apart from the fact that a strong genetic link exists between these two parameters (Praat et al., 2013). The noted correlation between $L^{*}$ and cooking loss (\%) or drip loss (\%) indicate the importance of IMF and water content of meat samples, as both influence lightness and losses during cooking or dripping.

In regard to IMF, it is generally, highly correlated with marbling score (Kruk et al., 2002; Lee and Choi, 2019). Therefore, the strong correlation observed between the IMF, as determined by Folch method, and the marbling content, estimated by in-silico approach, supports this notion. Our results are, also, in line with previously reported studies focusing on the relationship between intramuscular fat determined by chemical methods and image processing approaches. Giaretta et al. (2018) reported a high degree of correlation $(r=0.62)$ between the two approaches in an Angus beef study. Similarly, a high correlation coefficient $(r=0.66)$ reported in the case of crossbred beef samples (Silva et al., 2010). In contrast, an earlier study (Ishii et al., 1992) noted a low degree of correlation $(r=0.34)$ between the two methods due to weaknesses existed that era in image clarity and processing.

March 2022 | Volume 10 | Issue 3 | Page 511
Many studies have been previously conducted attempting to estimate marbling using non chemical methods (Konarska et al., 2017; Velásquez et al., 2017). Image analysis has been developed for objective evaluation of meat quality and further for evaluating meat marbling (Yang et al., 2006; Irie and Kohira, 2012; Lee et al., 2018). Image analysis is preferred as a method because it is: (a) less time-consuming and more affordable compared to other methods i.e., infrared spectroscopy or hyperspectral imaging technology; (b) non-invasive as it does not destroy the sample and (c) it can easily be used at slaughterhouses during carcasses evaluation. Based on the strong link observed between IMF and marbling values, we further proceed in a regression analysis in an attempt to predict IMF using marbling content estimated by image analysis. The estimated $\mathrm{R}^{2}(0.64)$ in our regression analysis revealed a moderate $\left(0.5<\mathrm{R}^{2}<0.7\right)$ predicting ability (Moore et al., 2013). Samples with marbling value $>2.5 \%$ did not fitted well in the determined regression line (Figure 3). This is due to the low representativeness of samples with a fat content more than 3\%, which did not allow for a better model prediction. However, as consumers' preferences (in Greece) are focused mainly on low or even with limited intramuscular fat content of beef portions, the implemented method could provide valuable information of IMF using marbling values estimated by image analysis. This, also, enforces the verification of such an approach in larger data sets, which could further assist the quick and facile marbling estimation under SEUROP system for consumers' needs or other breeding purposes.

\section{CONCLUSIONS AND RECOMMENDATIONS}

Beef meat quality characteristics were determined in samples obtained from breeds reared for beef purposes in Greece. Samples of Greek Red breed, showed a significant higher value of $a^{*}$ color parameter compared to samples obtained from crossbreds. In addition, meat samples from Holstein had a higher marbling content compared to the rest examined breed groups. Significant positive correlations were noted between some of the determined meat quality parameters. A significant strong correlation observed, also, between chemical determined IMF and marbling content, estimated by an image analysis approach. The regression analysis between IMF and marbling resulted in a moderate predicted ability of IMF based on marbling estimated by image analysis. A better fit on the model noted for low values of marbling $(<2.5 \%)$. Our findings provide novel information regarding meat quality of breeds reared for beef purposes in Greece and offer, also, a valuable tool for predicting IMF content using marbling values estimated by a non-invasive approach, enforcing, therefore, the implementation of such an approach in larger data sets. 


\section{ACKNOWLEDGEMENTS}

Authors would like to acknowledge farmers and meat retailers for providing voluntarily the meat samples used for the purposes of the present study.

\section{ETHICAL STATEMENT}

All experimental procedures were approved by the bioethical committee of the Agricultural University of Athens under the guidelines of Council Directive 86/609/EEC regarding the protection of animals used for experimental and other scientific purposes.

\section{NOVELTY STATEMENT}

The study provides novel information regarding meat quality of commercial beef carcasses in Greece and offers, also, a valuable and facile tool for predicting intramuscular fat content by using marbling values that have been previously estimated by an image analysis method.

\section{AUTHOR'S CONTRIBUTION}

MPK: experimental procedures, image analysis, data curation, original draft preparation; $\mathrm{KN}$ : experimental procedures, sampling, data curation, original draft preparation; LGP: in-silico methodology development, sampling, statistical analysis, supervision, editing, critically revised the manuscript, conceptualization; KP: data analysis, review and editing; BI: conceptualization, methodology, supervision, critically revised the manuscript.

\section{CONFLICT OF INTEREST}

The authors have declared no conflict of interest.

\section{REFERENCES}

American Meat Science Association (AMSA) (2001). National Cattlemen's Beef Association, and National Pork Producers Council. Meat evaluation handbook: Amer Meat Science Assn. USA.

Bonny SPF, Hocquette JF, Pethick DW, Legrand I, Wierzbicki J, Allen P, Farmer LJ, Polkinghorne RJ, Gardner GE (2018). The variability of the eating quality of beef can be reduced by predicting consumer satisfaction. Animal, 12: 2434-2442. https://doi.org/10.1017/S1751731118000605

Bosch L, Tor M, Reixach J, Estany J (2012). Age-related changes in intramuscular and subcutaneous fat content and fatty acid composition in growing pigs using longitudinal data. Meat Sci., 91(3): 358-363. https://doi.org/10.1016/j. meatsci.2012.02.019

Čandek-Potokar M, Prevolnik M, Škrlep M, Font-i-Furnols M, Novič, M (2015). An attempt to predict conformation and fatness in bulls by means of artificial neural networks using weight, age and breed composition information. Ital.J. Anim. Sci., 14: 45-52. https://doi.org/10.4081/ijas.2015.3198
Coleman LW, Hickson RE, Schreurs NM, Martin NP, Kenyon PR, Lopez-Villalobos N, Morris ST (2016). Carcass characteristics and meat quality of Hereford sired steers born to beef-cross-dairy and Angus breeding cows. Meat Sci.,121: 403-408. https://doi.org/10.1016/j.meatsci.2016.07.011

Craigie CR, Navajas EA, Purchas RW, Maltin CA, Bünger L, Hoskin SO, Ross DW, Morris ST, Roehe R (2012). A review of the development and use of video image analysis (VIA) for beef carcass evaluation as an alternative to the current EUROP system and other subjective systems. Meat Sci., 92: 307-318. https://doi.org/10.1016/j.meatsci.2012.05.028

Dinh TT, Blanton JR, Riley DG, Chase CC, Coleman SW, Phillips WA, Brooks JC, Miller MF, Thompson LD (2010). Intramuscular fat and fatty acid composition of longissimus muscle from divergent pure breeds of cattle. J. Anim. Sci., 88: 756-766. https://doi.org/10.2527/jas.2009-1951

Domestic Animal Diversity Information System (DAD-IS), FAO, 2021. http://www.fao.org/dad-is (accessed on 11 Nov 2021).

Ellies-Oury MP, Hocquette JF, Chriki S, Conanec A, Farmer LJ, Chavent M, Saracco J (2020). Various statistical approaches to assess and predict carcass and meat quality traits. Foods, 9: 525. https://doi.org/10.3390/foods9040525

Folch J, Lee M, Sloane Stanley GH (1957). A simple method for the isolation and purification of total lipids from animal tissues. J. Biol. Chem., 226: 497-509. https://doi. org/10.1016/S0021-9258(18)64849-5

Font-i-Furnols M, Realini C, Montossi F, Sañudo C, Campo MM, Oliver MA, Nute GR, Guerrero L (2011). Consumer's purchasing intention for lamb meat affected by country of origin, feeding system and meat price: A conjoint study in Spain, France and United Kingdom. Food Qual. Prefer., 22(5): 443-451. https://doi.org/10.1016/j. foodqual.2011.02.007

Food and Agriculture Organization of the United Nations. 1997. FAOSTAT Statistical Database. Rome: FAO (Access: Oct. 2021).

Giaretta E, Mordenti AL, Canestrari G, Brogna N, Palmonari A, ForAmigoni A (2018). Assessment of muscle Longissimus thoracis et lumborum marbling by image analysis and relationships between meat quality parameters. PLoS One, 13(8): e0202535. https://doi.org/10.1371/journal. pone. 0202535

IBM Corp. Released 2019. IBM SPSS statistics for windows, version 26.0. Armonk, NY: IBM Corp.

Immone K, Ruusunen M, Hissa K, Puolanne, E (2000). Bovine muscle glycogen concentration in relation to finishing diet, slaughter and ultimate $\mathrm{pH}$. Meat Sci., 55: 25-31. https:// doi.org/10.1016/S0309-1740(99)00121-7

Irie M, Kohira K (2012). Simple spot method of image analysis for evaluation of highly marbled beef. Anim. Biosci., 25(4): 592-596. https://doi.org/10.5713/ajas.2011.11204

Ishii T, Cassens RG, Scheller KK, Arp SC, Schaefer DM (1992). Image Analysis to determine intramuscular fat in muscle. Food Struct., 11(1): Article 6.

Konarska M, Kuchida K, Tarr G, Polkinghorne RJ (2017). Relationships between marbling measures across principal muscles. Meat Sci., 123: 67-78. https://doi.org/10.1016/j. meatsci.2016.09.005

Lee B, Choi YM (2019). Correlation of marbling characteristics with meat quality and histochemical characteristics in longissimus thoracis muscle from Hanwoo steers. Food Sci. Anim. Resour., 39(1): 151-161. https://doi.org/10.5851/ 
kosfa.2019.e12

Lee B, Yoon S, Lee Y, Oh E, Yun YK, Kim BD, Kuchida K, Oh HK, Choe J, Choi YM (2018). Comparison of marbling fleck characteristics and objective tenderness parameters with different marbling coarseness within longissimus thoracis muscle of high-marbled Hanwoo steer. Korean J. Food Sci. Anim. Resour., 38: 606-614.

Liu J, Chriki S, Ellies-Oury MP, Legrand I, Pogorzelski G, Wierzbicki J, Farmer L, Troy D, Polkinghorne R, Hocquette JF (2020). European conformation and fat scores of bovine carcasses are not good indicators of marbling. Meat Sci., 170: 108233. https://doi.org/10.1016/j.meatsci.2020.108233

Mancini RA, Hunt MC (2005). Current research in meat color. Meat Sci., 71: 100-121. https://doi.org/10.1016/j. meatsci.2005.03.003

Marenčić D, Ivanković A, Kozačinski L, PoPović M, CvrtIla $\check{Z}$ (2018). The effect of sex and age at slaughter on the physicochemical properties of baby-beef meat. Vet. Arhiv., 88: 101-110. https://doi.org/10.24099/vet.arhiv.160720

Miguel JA, Ciria J, Asenjo B, Pargas H, Colmenarez D (2011). Chemical composition of meat in castrated male Brahman cattle in Venezuela. J. Anim. Sci., 5: 562-568.

Monteiro ACG, Gomes E, Barreto AS, Silva MF, Fontes MA, Bessa RJB, Lemos JPC (2013). Eating quality of 'Vitela Tradicional do Montado'-PGI veal and MertolengaPDO veal and beef. Meat Sci., 94: 63-66. https://doi. org/10.1016/j.meatsci.2012.12.011

Moore DS, Notz WI, Flinger, MA (2013). The basic practice of statistics $\left(6^{\text {th }}\right.$ ed.). New York, NY: W.H. Freeman and Company. pp. 138.

Muchenje V, Dzama K, Chimonyo M, Strydom PE, Hugo A, Raats, JG (2008). Sensory evaluation and its relationship to physical meat quality attributes of beef from Nguni and Bonsmara steers raised on natural pasture. Animal, 2: 17001706. https://doi.org/10.1017/S1751731108002802

Nikolaou K, Koutsouli P, Bizelis I (2020). Evaluation of Greek Cattle Carcass Characteristics (Carcass Weight and Age of Slaughter) Based on SEUROP Classification System. Foods, 9: 1764. https://doi.org/10.3390/foods9121764

Page JK, Wulf DM, Schwotzer TR (2001). A survey of beef muscle color and pH. J. Anim. Sci., 79: 678-687. https:// doi.org/10.2527/2001.793678x

Polkinghorne RJ, Thompson JM (2010). Meat standards and grading. A world view. Meat Sci., 86: 227-235. https://doi. org/10.1016/j.meatsci.2010.05.010

Pratt PJ, Moser DW, Thompson LD, Jackson SP, Johnson BJ, Garmyn AJ, Miller MF (2013). The heritabilities, phenotypic correlations, and genetic correlations of lean color and palatability measures from longissimus muscle in beef cattle. J. Anim. Sci., 91(6): 2931-2937. https://doi. org/10.2527/jas.2012-5662

Prieto N, Navajas E, Richardson R, Ross D, Hyslop J, Simm G, Roehe R (2010). Predicting beef cuts composition, fatty acids and meat quality characteristics by spiral computed tomography. Meat Sci., 86(3): 770-779. https://doi. org/10.1016/j.meatsci.2010.06.020

Regulation (EU) No 1308/2013 of the European Parliament and of the Council of 17 December 2013 establishing a common organization of the markets in agricultural products and repealing Council Regulations (EEC) No 922/72, (EEC) No 234/79, (EC) No 1037/2001 and (EC) No 1234/2007. O. J. Eur. Union 2013, 347, 671. Available online: http:// data.europa.eu/eli/reg/2013/1308/2019-01-01.

Schneider CA, Rasband WS, Eliceiri KW (2012). NIH image to image J: 25 years of image analysis. Nat. Methods, 9(7): 671-675. https://doi.org/10.1038/nmeth.2089

Scollan ND, Hocquette JF, Nuernberg K, Dannenberger D, Richardson I, Moloney A (2006). Innovations in beef production systems that enhance the nutritional and health value of beef lipids and their relationship with meat quality. Meat Sci., 74: 17-33. https://doi.org/10.1016/j. meatsci.2006.05.002

Silva S, Patricio M, Guedes C, Mena E, Silva A, Santos V, Andre J, Cadavez V, Thiel D. (2010). Assessment of muscle Longissimus thoracis et lumborum intramuscular fat by ultrasonography and image analysis. $6^{\text {th }}$ International Conference on Simulation and Modelling in the Food and Bio-Industry Foodsim.

Velásquez L, Cruz-Tirado JP, Siche R, Quevedo R (2017). An application based on the decision tree to classify the marbling of beef by hyperspectral imaging. Meat Sci., 133: 43-50. https://doi.org/10.1016/j.meatsci.2017.06.002

Yang XJ, Albrecht E, Ende, K, Zhao RQ, Wegner J (2006). Computer image analysis of intramuscular adipocytes and marbling in the longissimus muscle of cattle. J. Anim. Sci., 84: 3251-3258. https://doi.org/10.2527/jas.2006-187

Zhang YY, Zan LS, Wang HB, Xin YP, Adoligbe CM, Ujan JA (2010). Effect of sex on meat quality characteristics of Qinchuan cattle. Afr. J. Biotechnol., 9: 4504-4509.

Kruk ZA, Pitchford WS, Siebert BD, Deland MP B, Bottem CDK (2002). Factors affecting estimation of marbling in cattle and the relationship between marbling scores and intramuscular fat. Anim. Prod. Aust., 24: 129-132. 